\title{
Humans hastened the range collapse and extinction of woolly mammoth
}

Damien A. Fordham ${ }^{1,2 *}$, Stuart C. Brown ${ }^{1}$, H. Reşit Akçakaya ${ }^{3}$, Barry W. Brook ${ }^{4}$, Sean Haythorne $^{1}$, Andrea Manica ${ }^{5}$, Kevin T. Shoemaker ${ }^{6}$, Jeremy J. Austin ${ }^{1}$, Benjamin Blonder ${ }^{7}$, Julia Pilowsky $^{1,2}$, Carsten Rahbek ${ }^{2,8,9,10}$, David Nogues-Bravo ${ }^{2}$.

${ }^{1}$ The Environment Institute and School of Biological Sciences, University of Adelaide, South Australia 5005, Australia.

${ }^{2}$ Center for Macroecology, Evolution, and Climate, GLOBE Institute, University of Copenhagen, Copenhagen, Denmark

${ }^{3}$ Department of Ecology and Evolution, Stony Brook University Stony Brook, New York 11794, USA

${ }^{4}$ School of Natural Sciences and ARC Centre of Excellence for Australian Biodiversity and Heritage, University of Tasmania, Hobart, Tasmania 7001, Australia

${ }^{5}$ Department of Zoology, University of Cambridge, Downing Street, Cambridge, CB2 3EJ, UK

${ }^{6}$ Department of Natural Resources and Environmental Science, University of Nevada, Reno, NV, US

${ }^{7}$ Department of Environmental Science, Policy, and Management, University of California, Berkeley, CA, 94706, USA

${ }^{8}$ Department of Life Sciences, Imperial College London, Ascot SL5 7PY, UK

${ }^{9}$ Danish Institute for Advanced Study, University of Southern Denmark, Odense, Denmark.

${ }^{10}$ Institute of Ecology, Peking University, Beijing 100871, China

*Correspondence to: $\underline{\text { damien.fordham } @ \text { adelaide.edu.au }}$

\begin{abstract}
Processes leading to the megafauna extinctions of the late Pleistocene and early-Holocene are uncertain, with intense debate on the roles of human hunting and climatic change. Using processexplicit simulations of climate-human-woolly mammoth interactions, which integrate spatiotemporal evidence from fossils and ancient DNA, we show that humans accelerated the timing of range collapse, extirpation and eventual extinction of woolly mammoth in Eurasia. Population growth and northward migrations of people during the late Pleistocene led to the premature extirpation of populations of woolly mammoth in areas of Eurasia that were climatically suitable into the Holocene, hastening climate-driven declines by up to 4,000 years in some regions. Our simulations also pinpoint mainland Arctic refugia where mammoths likely persisted until the mid-Holocene, some 5,000 years longer than previously thought. Our results reveal that the role of humans in the extinction dynamics of woolly mammoth was long and chronic, and not limited to a Holocene over-kill.
\end{abstract}




\section{Introduction}

Global warming following the Last Glacial Maximum through to the early Holocene (approximately 19 to $11 \mathrm{ka} \mathrm{BP}$ ) resulted in regional temperature increases of 4 to $>10^{\circ} \mathrm{C}(1)$. During this deglaciation phase, many megafaunal species (terrestrial taxa $>45 \mathrm{~kg}$ ) became extinct (2) and many others suffered regional extirpations (3). This biotic simplification radically changed the structure and function of ecosystems $(4,5)$. At the same time, Paleolithic human populations were spreading and becoming more ubiquitous, facilitated by increases in primary productivity associated with climatic change $(6,7)$. What has remained fiercely contested is the relative role of human hunting and climate change, or a synergy of these impacts, on the fate of the megafauna $(2,3,8-12)$. Major barriers to a resolution include a sparse and uncertain fossil record (13), a lack of high-resolution spatiotemporal projections of climatic change and human abundances (14), and a reliance on correlative rather than process-based approaches to infer drivers of extinction (15).

Recent developments in macroecological modelling are enabling the drivers and processes of megafauna extinctions to be unraveled using a wide body of evidence from paleo-archives (15). These novel approaches, which simulate the dynamics of a biological system as explicit functions of the events that drive change in that system (16), offer fresh opportunities to visualize and disentangle ecological responses to climate- and human-driven changes in species distributions and abundances across space and time (17). Unlike correlative approaches, fossil and molecular signatures of past demographic change are used as independent, objective targets in this new pattern-oriented approach for evaluating a model's structural adequacy and parameterization (18). This allows the relevant global change drivers and biological processes important to population and geographic range dynamics to be simulated and tested, revealing the most likely chains of causality that lead to extinction (15).

The iconic woolly mammoth (Mammuthus primigenius) was present on earth for more than half a million years (19) before going extinct in the mid-Holocene (11). During this time woolly mammoths co-existed with Neanderthals (Homo neanderthalensis) and modern humans (H. sapiens) for many millennia, and were exploited for meat, skins, bones and ivory (9-11). As the earth warmed rapidly during the last deglaciation, boreal forests spread throughout Eurasia, 
replacing tundra grassland and forbs (20), the preferred habitat for woolly mammoths. Previous process-explicit examinations of the extinction dynamics of woolly mammoth have focused, largely, on the effect of a small population size on persistence (21-23), concluding that genomic meltdown through inbreeding caused its extinction $(21,22)$. However, improved knowledge of biological processes and drivers of early-stage population declines is required to unravel causes of extinction (24).

Where lasting roles of climate and humans have been previously considered, their function in setting the location and timing of woolly mammoth extinction has been inferred from snapshots (points in time $\geq 12,000$ years apart) of projected historical range movement $(8,9)$ and analysis of time-binned fossil and archaeological data $(11,12)$, both using correlative (not processexplicit) techniques. This has, until now, precluded complex causal stressors and ecological processes from being teased apart spatiotemporally and, therefore, understood.

To explain the range collapse, population decline and extinction of woolly mammoth in Eurasia, we built a process-explicit spatially dynamic simulation model where climate and humans can affect the population dynamics of woolly mammoths from $21 \mathrm{ka} \mathrm{BP}$. We explored $>90,000$ scenarios, deriving best estimates of model parameters using the paleo-record. Radiocarbon $\left({ }^{14} \mathrm{C}\right)$ dated and georeferenced fossils, and ancient DNA were used to reconstruct a long-term time series of changes in population size and the timing and location of extinction. These spatiotemporal inferences of local extinctions and demographic change were then used as validation targets to identify models with the right combination of biological processes (demographic constraints for movement and extinction) and rates of global change (humanimpact, climate-change and their interaction) needed to accurately simulate the spatiotemporal extinction dynamics of woolly mammoth. Our pattern-oriented method (18) allowed biological mechanisms crucial to the population dynamics and eventual extinction of the species to be disentangled.

\section{Results \\ Holocene refugia}

The best models (top 1\% of all models, which most closely hit the validation targets) reconstruct a north-eastward range contraction for woolly mammoth from 19 ka BP (11), with extirpation in 
most of Europe by 14 ka BP (Fig. 1; Movie S1), with the exception of refugial areas in what is now Britain, northern France and Belgium (as well as the Netherlands and Denmark), where pockets of steppe-tundra ecosystems are likely to have persisted until the termination of the Pleistocene (20).

These best models simulate an accelerated rate of range collapse in Asia following rapid warming at $\sim 15 \mathrm{ka} \mathrm{BP}$ (Fig. 1; Movie S1), with populations persisting in Siberian refugia in Taimyr, Beringia and the Yamal Peninsula, in accordance with fossil remains $(10,11)$.

Moreover, these models accurately project a steep decline in total population size during the Late Pleistocene (Fig. 1), as has been inferred from ancient DNA estimates of effective population size (25).

Our simulations, however, do not project a continent-wide extirpation during the early Holocene, as has been previously inferred from fossil records $(11,26)$. Instead, we project persistence within refugia in Beringia, along the Kara Sea and in northern Fennoscandia (following the retreat of glacial ice sheets) until at least the mid-Holocene (Fig. 1; Movie S1-S2). Refugia projected in high elevation plateau areas of southern Asia during the Holocene (Fig. 1) have low model agreement (Methods): on average $<9 \%$ probability of occurrence (Movie S1). Likewise, confidence in the occupancy of Svalbard by mammoths is low (Movie S1).

Consensus projections of mainland refugia in the Arctic during the Holocene (Fig. 1; Movie S1S2) pinpoint likely locations of yet-to-be-discovered refugia (and fossils) (13), considering the incompleteness of the fossil record (Fig. S1), the mid-Holocene persistence of indicator species of mammoth in Siberia (27) and projected low population numbers of mammoths in the Holocene (Fig. 1). Moreover, using the fossil record alone to conclude time of regional extirpation and range-wide extinction for woolly mammoth (and other megafauna) has resulted previously in persistence being underestimated by several millennia (13). Previous estimates of regional and range-wide extinction for megafauna (including woolly mammoth) using the fossil record alone have resulted in persistence being underestimated by several millennia (13). 


\section{Range collapse and extinction}

We show that correctly simulating vital aspects of the range collapse and extinction of woolly mammoth for continental Eurasia requires the operation of very specific climatic requirements (niche marginality) and demographic processes (Allee effect, and maximum density of mammoth) (Fig. S2; Table S1). These findings confirm that climatic change and individual fitness at small population sizes are likely to have had important roles in the extinction dynamics of woolly mammoth in Eurasia $(9,22)$.

Across Eurasia, climatic change during the last deglaciation and Holocene affected the geography of human and woolly-mammoth abundance differently based on the best validated simulations of climate-human-woolly mammoth interactions (Fig. 2). Accelerated warming following Heinrich Event 1 ( $17.5 \mathrm{ka} \mathrm{BP})$ resulted in climatically preferred conditions (temperature and precipitation) for mammoths and humans becoming decoupled (mean Lee's L statistic of spatial autocorrelation $=-0.07$ between 17.5 and $15 \mathrm{ka} \mathrm{BP}$ ), due likely to humans responding to environmental change by colonizing and remaining resident in new niches (28), and the woolly mammoth becoming increasingly restricted to the coldest areas of its climatic niche.

Using statistical learning models to identify spatiotemporal determinants of extinction risk (29), we show that climatic shifts alone during the last deglaciation explain 52 and $57 \%$ of the variance in expected minimum abundance (EMA, a common measure of extinction risk; Methods) of woolly mammoth in Eurasia at $15 \mathrm{ka} \mathrm{BP}$ and $11 \mathrm{ka}$ BP, respectively (Fig. 2). Larger magnitudes of change in the climatic conditions suitable for woolly mammoth persistence, along with a faster pace of loss of these conditions in the Arctic increased the extinction risk during the periods 21-15 ka BP (T1) and 15-11 ka BP (T2) (Fig. S3). The magnitude and pace of human population growth (Methods) became as important as climatic change during the Holocene in influencing the EMA of woolly mammoth in Eurasia at $5 \mathrm{ka} \mathrm{BP}$ (Fig. 2). A lower explained variance compared to earlier time periods (Fig. 2) results from validation procedures retaining models that simulate mechanisms of late-Pleistocene range collapse and population decline (those occurring in T1 and T2) having a long-lasting effect on the timing and location of extinction in the Holocene (T3; 11-5 ka BP). While exploitation of woolly mammoths by 
humans was probably decisive in its final range-wide extinction during the mid-Holocene, demographic responses to impacts of humans and climate varied temporally across regions.

\section{Regional variation in extinction drivers}

Populations of woolly mammoths in distinct regions of Eurasia experienced different magnitudes of human and climate impacts over time (Fig. S4), suggesting that the dynamics of extinction determinants were labile. We found that humans impacted demographic processes of woolly mammoth prior to the Holocene in Europe. The magnitude and pace of human and climate impacts during the last deglaciation in Europe explained relatively similar amounts of variance in EMA of woolly mammoth (Fig. 3). Humans and mammoths responded differently to climate change during this interval in Europe (mean Lee's $L=0.21$ for the last deglaciation, indicating low autocorrelation), signifying direct and important roles of hunting and climate change on mammoth EMA. Therefore, humans are likely to have had a far more sustained effect on the population dynamics and extirpation of woolly mammoths in Europe than previously thought (3, 9, 10). For the few populations in northern Fennoscandia that were simulated to have colonized the region following the retreat of glacial ice sheets (Movie S1-S2), gradual climatic change during the Holocene was the greatest threat to simulated persistence (Fig. 3) not hunting by humans, which remained relatively low (Movie S3), owing to low human population densities in northern Fennoscandia (Movie S4).

In Asia and Beringia, the role of humans on the range collapse and extirpation of woolly mammoth more closely mirror the pattern of continent-wide extinction observed for Eurasia, with humans having a proportionately larger threatening influence on EMA by the Holocene (Fig. S4). In Beringia, climatic changes during the last deglaciation and Holocene affected humans and mammoths more similarly than for other regions of Eurasia (Fig. S4; mean Lee's L $=0.44$ for the last deglaciation; and 0.35 for the Holocene), indicating greater synchrony in shifts in range and abundance.

\section{Human-mammoth interactions}

Our process-explicit modelling approach also permits possible alternatives to past events to be simulated and the biological consequences assessed (15). Counterfactual models with no 
mammoth exploitation by humans provide further evidence that humans hastened the timing of range collapse and extinction of woolly mammoths. By holding human-hunting parameters constant in the best $1 \%$ of validated models and then analyzing the effect on dynamical processes and emergent patterns, we show that in the absence of humans (and their interactions with climate change), woolly mammoths would have been more abundant across time, and populations would have persisted for much longer, perhaps even avoiding extinction within climatic refugia (Fig. 4). Mid-to-late Holocene population sizes of woolly mammoths were much larger in simulations in the absence of human harvesting (Table S2), causing a 24\% increase in persistence beyond $3.8 \mathrm{ka} \mathrm{BP}$; the estimated time of extinction $(95 \%$ confidence interval $=4089$ to $3450 \mathrm{BP}$ ) based on the fossil record (Supplementary Material). Although some model simulations with humans did not result in range-wide extinction by $3.8 \mathrm{ka}$ BP (Fig. S5), confidence intervals for expected minimum abundances intersect zero (Table S2).

While simulations of mammoth abundance, with and without humans, were asynchronous (except for Beringia prior to $15 \mathrm{ka} \mathrm{BP}$ ), the extreme peaks and troughs in abundance generally occurred at similar times in the simulations (Table S3). This was not the case for Europe during the early part of the last deglaciation $(21-15 \mathrm{ka} \mathrm{BP})$ and Asia during the latter part of the last deglaciation (15 - $11 \mathrm{ka} \mathrm{BP})$, confirming that the strength of the regulatory role of humans on the extinction dynamics of woolly mammoth was regionally and temporally variable.

\section{Discussion}

Our validated reconstructions of the extinction dynamics of woolly mammoths show that range collapse and extinction is likely to have resulted from demographic responses to spatially and temporally variant rates of climatic change and human impacts since the Last Glacial Maximum, and their synergy, revealing that mammoths likely persisted in mainland Arctic refugia until the mid-Holocene. We show that population growth and northward migrations of people during the late Pleistocene led to the premature extirpation of populations of woolly mammoth in areas of Eurasia that were climatically suitable into the Holocene, hastening climate-driven declines by up to 4,000 years in some regions. 
The role of humans as a causative agent in the extinction of woolly mammoths is likely to have been both direct and indirect. In addition to exploitation-driven changes in demographic processes, the climate-change-facilitated co-occupation of steppe and forb habitats by humans and woolly mammoths could have affected metapopulation structures and processes by interrupting sub-population connectivity, affecting movement between resource-rich zones (3). Posterior distributions for exploitation parameters (including harvest rate) for Eurasia-wide simulations more closely matched prior distributions when compared to some climate and demographic parameters (Fig. S2; Table S1). A reduced importance of the role of human hunting in the extinction dynamics of woolly mammoth at a continental scale likely reflects variable rates of hunting of woolly mammoths by humans in space and time (Fig. S4) and a likelihood that, to some extent, humans impacted mammoth metapopulation processes independent of hunting (e.g., via habitat change).

Correctly simulating spatiotemporal evidence of extinction dynamics inferred from fossils and ancient DNA, required persistence in mainland Arctic refugia until the mid-Holocene, some 5,000 years longer than previously thought. Although equifinality was avoided in our analyses, through the use of multiple validation targets, our finding that mammoths likely persisted in mainland refugia in Eurasia until the mid-Holocene remains dependent on inferences of extinction from the fossil record, estimates of population decline from ancient DNA, and projections of spatially and temporally variant rates of climatic change and human impacts. While the fossil record for woolly mammoth, during the Pleistocene-Holocene transition, is more complete then for many other megafauna species, there are still vast areas of Eurasia which remain poorly sampled (Fig. S1). Likewise, projections of population growth and migrations of people during the late Pleistocene and Holocene do not yet account for topographical processes and cultural changes $(6,7)$, which could potentially influence our results.

Our analyses strengthen and better resolves the case for human impacts as a crucial and chronic driver of early-stage population declines of megafauna, revealing an essential role of humans in population declines of mammoths in Eurasia during the late Pleistocene; a period when climatic conditions warmed rapidly. In doing so, it refutes a prevalent theory that the role of humans in the extinction dynamics of woolly mammoths was limited to a mid-Holocene coup de grâce (9), 
and highlights the importance of disentangling demographic responses to varying biotic and abiotic stressors for metapopulations at regional scales, particularly when assessing species survival.

\section{Materials and Methods}

Experimental design

To explain the range collapse, population decline and extinction of woolly mammoth in Eurasia, we built a process-explicit spatially dynamic simulation model where climate and humans could affect the population dynamics of woolly mammoths from $21 \mathrm{ka}$ BP. Spatiotemporal patterns inferred from the fossil record and ancient DNA were used as filters for evaluating whether a model is adequate in its structure and parameterization to simulate the underlying processes. The process-explicit model is described in detail in Appendix 1 in (30).

\section{Fossil data}

Radiocarbon dated and georeferenced fossils for M. primigenius during the Late Pleistocene and Holocene were sourced from publicly accessible databases and the published literature (30). Their age reliability was assessed (31) and all reliable ages were calibrated using OxCal (32) and the IntCal13 calibration curve (33). The fossil record and associated metadata is available in Appendix 3 of Fordham and Brown (30).

\section{Climate change and woolly mammoths}

Climate-woolly mammoth interactions were characterized by an n-dimensional hypervolume (34) of climatic suitability through time (35). To do this we intersected fossil locations and time periods (calibrated age $\pm 1 \mathrm{SD}$ ) with paleoclimate simulations of climatic parameters $(36,37)$ that affect the population dynamics of large herbivores (38), including those in polar regions (Appendix 1 in (30)). Variables included average minimum daily temperature in January, average maximum daily temperature in July, and average daily precipitation in summer (Fig. S7). Together they provide a biologically relevant representation of the climate history over which woolly mammoths were likely to have been present at fossil sites (39).

The TraCE-21 simulation of the transient climate of the last 21,000 years was accessed using PaleoView (36) and used to generate 30-year average estimates of monthly mean parameters at 
25-year time steps (generation length for woolly mammoths; Appendix 1 in (30)) for the period $21 \mathrm{ka} \mathrm{BP}$ to $0 \mathrm{BP}$. The HadCM3 paleoclimate simulations from 60 to $21 \mathrm{ka} \mathrm{BP}$ were used to extend the breadth of climatic conditions that woolly mammoths can tolerate in the model. Climate data were harmonized and resampled to a $1 \times 1^{\circ}$ resolution (Appendix 1 in (30)).

The resulting multi-temporal 3-dimensional hypervolume of climate suitability approximated the fundamental niche (35), which we exhaustively subsampled to determine the realized niche (17), using pattern-oriented methods (18). The geometry of the hypervolume was measured using the R package 'hypervolume' (40) and checked for occupied and unoccupied hypervolume space (Extended data Figure 7) as a potential indicator of unconsidered climatic space (41). Subsampling was done using Outlier Mean Index (OMI) analysis, using plausible bounds of niche marginality (climatic specialization) and niche breadth (42), which measure the difference between the mean climate conditions in the niche sample and those in the full hypervolume (marginality), and the variability of climatic conditions in the niche sample (breadth). Spatial projections of climate suitability for woolly mammoths in Eurasia were generated from 21 ka to $0 \mathrm{BP}$ at 25-year time steps for each climate niche $(\mathrm{n}=1,862)$. We used a standard maximum entropy method (43) to project climate suitability because it is computationally faster than the kernel density hypervolume method and produces similar results (44). Projections of climate suitability accounted for latitudinal variation in grid cell size and temporal variation in the proportion of a cell that are land or sea ice (Appendix 1 in (30)).

\section{Humans}

The peopling of Eurasia by Paleolithic humans was modelled using a Climate Informed Population Genetics Model (CISGEM) that accurately reconstructs arrival times of anatomically modern humans and current-day distributions of global and regional genetic diversity $(6,45)$. More specifically CISGEM simulates local effective population sizes $\left(\mathrm{N}_{\mathrm{e}}\right)$ as a function of genetic history, local demography and paleoclimate (annual temperature and precipitation) and vegetation (net primary productivity) $(6,45)$. Like other numerical models of early human migration (7), arrival, occupancy and density (here $\mathrm{N}_{\mathrm{e}}$ ) are forced by spatiotemporal estimates of climate and sea level changes over the past 125 thousand years. 
For each grid cell of $1 \times 1^{\circ}$ resolution in Eurasia, we used CISGEM to calculate a time series of effective population size $\left(\mathrm{N}_{\mathrm{e}}\right)$ from 21 ka to $0 \mathrm{BP}$ at 25-year time steps, following a burn-in period of approximately 80 generations (2,000 years). To account for parameter uncertainty in spatiotemporal projections of $\mathrm{N}_{\mathrm{e}}$ we ran 4,000 different models each with a unique combination of parameter settings (based on established upper and lower confidence bounds; $\sigma$ ) by means of Latin hypercube sampling (46). An upper plausible threshold for $\mathrm{N}_{\mathrm{e}}$ was set at 500 individuals per grid-cell based on estimates of true abundance in modern-day hunter-gatherer societies (47). We calculated average $\mathrm{N}_{\mathrm{e}} \pm 1 \mathrm{SD}$ for each time step at each grid cell and then generated 10,000 plausible reconstructions of human population abundance. CISGEM and its application is described in more detail in the Appendix 1 in (30).

\section{Climate-human-woolly mammoth interactions}

A process-explicit spatial model was used to simulate climate-human-woolly mammoth interactions at 25-year generational time steps from $21 \mathrm{ka} \mathrm{BP.} \mathrm{Extinction} \mathrm{and} \mathrm{colonization}$ dynamics were simulated as landscape-level population processes. Models built using 'best estimates' for demographic parameters and environmental attributes were varied across wide but plausible ranges using Latin hypercube sampling to provide a robust coverage of multidimensional parameter space (48). This procedure produced $>90,000$ conceivable models with different combinations of rates of climate change, hunting by humans and demographic processes. Each model was run for a single replicate (49). The model was coded in Program R, and is available here: https://github.com/GlobalEcologyLab/Mammoth. It is described in detail in Appendix 1 in (30).

Upper abundance for each cell was based on climate suitability (50). Upper abundance at maximum climate suitability varied between 0.25 and 4 animals per square kilometer. The lower estimate was for African elephants (Loxodonta africana) (51) and the upper estimate proposed for woolly mammoths (9). Long-term population-dynamics time-series data for L. africana were used to calculate finite rates of population increase and their variance (52). We scaled lambda (R0) to the generation level by taking the exponent: parameter range of maximum $\mathrm{R} 0=1.28-$ 6.85. The upper and lower bounds for $\mathrm{SD}_{\mathrm{R} 0}$ were set at 0 to 0.175 . Density dependence was modelled using a Beverton-Holt type density dependent response (53), where most compensation 
in vital rates occurs at population sizes close to carrying capacity. We simulated mammoths as being highly mobile based on allometry (54). We modelled dispersal rates of $5-25 \%$ of the population moving per generation at an average maximum distance of $100-500 \mathrm{~km}$.

Genetic evidence indicates a negative Allee effect prior to the extinction of the woolly mammoth due to inbreeding (22). To capture this without the need of a detailed genetic sub-model, we set a local quasi-extinction threshold (55) which made cell abundance zero if abundance fell below the Allee threshold. The range of values for the Allee effect were 0 (no Allee effect) to 500 mammoths per grid cell. The upper estimate is equivalent to $5 \%$ of max population abundance in a highly suitable cell.

Human hunting of mammoths in a grid cell at a point in time was simulated as a function of relative $\mathrm{N}_{\mathrm{e}}$ for humans, with maximum offtake rates varying from zero to $35 \%$ of woolly mammoth population abundance. The functional response was allowed to vary from a Type II to Type III response (56). We did not model a numerical response because the human population in Eurasia were not obligate hunters of mammoths, evident by exponential long-term growth of humans in Eurasia during the early-to-mid Holocene $(57,58)$.

\section{Statistical analyses}

Pattern-oriented modelling (18) was used to evaluate whether a model is adequate in its structure and parameterization to simulate process-explicit responses to climate change and humans, by cross-matching multiple lines of evidence from paleo-archives (15). Model simulations of changes in range area, extirpation pattern, total population size, and location of the last remaining population/populations were assessed using a multivariate target based on: trend in $\mathrm{N}_{\mathrm{e}}$ inferred from $M$. primigenius ancient DNA (a proxy for change in total population size; 8 ); time and location of range-wide extinction (from the fossil record, corrected for the Signor-Lipps effect; 59); and occupancy at fossil sites.

Approximate Bayesian Computation $(\mathrm{ABC} ; 60)$ was used to determine models that better replicated the range dynamics of woolly mammoth during the late Pleistocene and Holocene. The ABC approach provided a systematic way of assessing support for different model versions and parameterizations based on available validation data, given some prior beliefs about how likely they are (61). We retained the top $1 \%$ of feasible parameterizations of climate-human- 
woolly mammoth interactions $(n=900)$. Output from these models were used to generate an ensemble average of timing of extirpation (extinction at the grid cell), probability of occupancy, and total population abundance. Estimates were weighted by the Euclidean distance of the model from the idealized targets. Probability of occupancy was determined by producing binary presence/absence maps for each time step for each of the $900 \mathrm{ABC}$ selected simulations. These binary presence absence maps were then combined to generate ensemble weighted probability of occurrence using weights from the ABC analysis (Appendix 1 in (30)).

Models that most accurately reconstructed the timing and location of extinction and rate of decline of relative abundance, as inferred from fossils and ancient DNA, were used to reveal the causative roles of magnitude and pace of climate change and human population growth and expansion on the population collapse of woolly mammoth following the Last Glacial Maximum and its eventual extinction in the mid-to-late Holocene. To identify and evaluate the processes and drivers that caused the early-stage population collapse of woolly mammoth and later the susceptibility of small residual populations to eventual extinction (declining and small population paradigms; 24) we discretized each simulation into three distinct climatic periods (T1 $=21-15 \mathrm{ka} \mathrm{BP}, \mathrm{T} 2=15-11 \mathrm{ka} \mathrm{BP}$ and T3 = 11-5 ka BP) (1). For each of the periods and regions (including all of Eurasia) metrics quantifying the causative roles of magnitude and pace of climate change and human population growth and expansion were computed (30). We calculated extinction risk as Expected Minimum Abundance (EMA) at the termination of each period for the whole of continental Eurasia, and separately for the three distinct subregions (Europe, Asia, Beringia), quantifying risks of both overall population decline (quasi-extinction) and total extinction (62). Statistical learning models (63) were used to identify spatiotemporal determinants of extinction risk (29). Spatiotemporal autocorrelation between climatic and human drivers of extinction was calculated using the Lee's L Statistic (64). 


\section{References}

1. P. U. Clark et al., Global climate evolution during the last deglaciation. Proc Natl Acad Sci U S A 109, E1134-1142 (2012).

2. A. D. Barnosky, P. L. Koch, R. S. Feranec, S. L. Wing, A. B. Shabel, Assessing the Causes of Late Pleistocene Extinctions on the Continents. Science 306, 70 (2004).

3. A. Cooper et al., Abrupt warming events drove Late Pleistocene Holarctic megafaunal turnover. Science 349, 602-606 (2015).

4. J. L. Gill, J. W. Williams, S. T. Jackson, K. B. Lininger, G. S. Robinson, Pleistocene megafaunal collapse, novel plant communities, and enhanced fire regimes in North America. Science 326, 1100-1103 (2009).

5. C. E. Doughty et al., Global nutrient transport in a world of giants. Proc Natl Acad Sci U $S A$ 113, 868-873 (2016).

6. A. Eriksson et al., Late Pleistocene climate change and the global expansion of anatomically modern humans. Proc Natl Acad Sci U S A 109, 16089-16094 (2012).

7. A. Timmermann, T. Friedrich, Late Pleistocene climate drivers of early human migration. Nature 538, 92-95 (2016).

8. E. D. Lorenzen et al., Species-specific responses of Late Quaternary megafauna to climate and humans. Nature 479, 359-364 (2011).

9. D. Nogués-Bravo, J. Rodríguez, J. Hortal, P. Batra, M. B. Araújo, Climate Change, Humans, and the Extinction of the Woolly Mammoth. PLoS Biol 6, e79 (2008).

10. A. J. Stuart, The extinction of woolly mammoth (Mammuthus primigenius) and straighttusked elephant (Palaeoloxodon antiquus) in Europe. Quaternary International 126-128, 171-177 (2005).

11. A. J. Stuart, P. A. Kosintsev, T. F. G. Higham, A. M. Lister, Pleistocene to Holocene extinction dynamics in giant deer and woolly mammoth. Nature 431, 684-689 (2004).

12. G. M. MacDonald et al., Pattern of extinction of the woolly mammoth in Beringia. Nat Commun 3, 893 (2012).

13. J. Haile et al., Ancient DNA reveals late survival of mammoth and horse in interior Alaska. Proc Natl Acad Sci US A 106, 22352-22357 (2009).

14. D. A. Fordham, F. Saltré, S. C. Brown, C. Mellin, T. M. L. Wigley, Why decadal to century timescale palaeoclimate data are needed to explain present-day patterns of biological diversity and change. Glob. Change Biol. 24, 1371-1381 (2018). 
15. D. A. Fordham et al., Using paleo-archives to safeguard biodiversity under climate change. Science 369, eabc5654 (2020).

16. T. F. Rangel et al., Modeling the ecology and evolution of biodiversity: Biogeographical cradles, museums, and graves. Science 361, eaar5452 (2018).

17. D. A. Fordham et al., Predicting and mitigating future biodiversity loss using long-term ecological proxies. Nat Clim Change 6, 909-916 (2016).

18. V. Grimm et al., Pattern-Oriented Modeling of Agent-Based Complex Systems: Lessons from Ecology. Science 310, 987 (2005).

19. D. Chang et al., The evolutionary and phylogeographic history of woolly mammoths: a comprehensive mitogenomic analysis. Scientific Reports 7, 44585 (2017).

20. H. Binney et al., Vegetation of Eurasia from the last glacial maximum to present: Key biogeographic patterns. Quaternary Science Reviews 157, 80-97 (2017).

21. R. L. Rogers, M. Slatkin, Excess of genomic defects in a woolly mammoth on Wrangel island. PLoS Genetics 13, e1006601 (2017).

22. E. Palkopoulou et al., Complete genomes reveal signatures of demographic and genetic declines in the woolly mammoth. Curr Biol 25, 1395-1400 (2015).

23. R. W. Graham et al., Timing and causes of mid-Holocene mammoth extinction on St. Paul Island, Alaska. Proc Natl Acad Sci U S A 113, 9310-9314 (2016).

24. G. Caughley, Directions in Conservation Biology. J Anim Ecol 63, 215-244 (1994).

25. E. Palkopoulou et al., Holarctic genetic structure and range dynamics in the woolly mammoth. Proc. R. Soc. B-Biol. Sci. 280, 20131910 (2013).

26. P. A. Nikolskiy, L. D. Sulerzhitsky, V. V. Pitulko, Last straw versus Blitzkrieg overkill: Climate-driven changes in the Arctic Siberian mammoth population and the Late Pleistocene extinction problem. Quaternary Science Reviews 30, 2309-2328 (2011).

27. G. G. Boeskorov, Survival of indicator species of the mammoth fauna large mammals in the Holocene of Yakutia (East Siberia, Russia). IOP Conference Series: Earth and Environmental Science 438, 012004 (2020).

28. K. Giampoudakis et al., Niche dynamics of Palaeolithic modern humans during the settlement of the Palaearctic. Glob. Ecol. Biogeogr. 26, 359-370 (2017).

29. R. G. Pearson et al., Life history and spatial traits predict extinction risk due to climate change. Nat Clim Change 4, 217-221 (2014). 
30. D. Fordham, S. C. Brown. Appendix 1 - 4 for Humans hastened the range collapse and extinction of woolly mammoth. doi:10.25909/5f22592242ca2 (2020) Figshare.

31. A. D. Barnosky, E. L. Lindsey, Timing of Quaternary megafaunal extinction in South America in relation to human arrival and climate change. Quaternary International 217, 10-29 (2010).

32. C. Bronk Ramsey, Bayesian Analysis of Radiocarbon Dates. Radiocarbon 51, 337-360 (2009).

33. P. J. Reimer et al., IntCal13 and Marine13 Radiocarbon Age Calibration Curves 050,000 Years cal BP. Radiocarbon 55, 1869-1887 (2013).

34. G. E. Hutchinson, Population studies: Animal ecology and demography - concluding remarks. Cold Spring Harb Symp Quant Biol 22, 415-427 (1957).

35. D. Nogués-Bravo, Predicting the past distribution of species climatic niches. Glob. Ecol. Biogeogr. 18, 521-531 (2009).

36. D. A. Fordham et al., PaleoView: a tool for generating continuous climate projections spanning the last 21000 years at regional and global scales. Ecography 40, 1348-1358 (2017).

37. J. S. Singarayer, P. J. Valdes, High-latitude climate sensitivity to ice-sheet forcing over the last 120 kyr. Quaternary Science Reviews 29, 43-55 (2010).

38. B.-E. Sæther, Environmental stochasticity and population dynamics of large herbivores: a search for mechanisms. Trends Ecol Evol 12, 143-149 (1997).

39. D. A. Fordham, B. W. Brook, C. Moritz, D. Nogues-Bravo, Better forecasts of range dynamics using genetic data. Trends Ecol Evol 29, 436-443 (2014).

40. B. Blonder, C. Lamanna, C. Violle, B. J. Enquist, The n-dimensional hypervolume. Glob. Ecol. Biogeogr. 23, 595-609 (2014).

41. B. Blonder, Do Hypervolumes Have Holes? Am Nat 187, E93-105 (2016).

42. S. Dolédec, D. Chessel, C. Gimaret-Carpentier, Niche separation in community analysis: A new method. Ecology 81, 2914-2927 (2000).

43. S. J. Phillips, R. P. Anderson, R. E. Schapire, Maximum entropy modeling of species geographic distributions. Ecol. Model. 190, 231-259 (2006).

44. B. Blonder et al., New approaches for delineating n-dimensional hypervolumes. Methods Ecol Evol 9, 305-319 (2018). 
45. M. Raghavan et al., Genomic evidence for the Pleistocene and recent population history of Native Americans. Science 349, aab3884 (2015).

46. M. D. McKay, R. J. Beckman, W. J. Conover, A Comparison of Three Methods for Selecting Values of Input Variables in the Analysis of Output from a Computer Code. Technometrics 21, 239-245 (1979).

47. L. R. Binford, Constructing frames of reference: an analytical method for archaeological theory building using ethnographic and environmental data sets. (Univ of California Press, 2001).

48. D. A. Fordham, S. Haythorne, B. W. Brook, Sensitivity Analysis of Range Dynamics Models (SARDM): Quantifying the influence of parameter uncertainty on forecasts of extinction risk from global change. Environmental Modelling \& Software 83, 193-197 (2016).

49. T. A. A. Prowse et al., An efficient protocol for the global sensitivity analysis of stochastic ecological models. Ecosphere 7, e01238 (2016).

50. J. VanDerWal, Luke P. Shoo, Christopher N. Johnson, Stephen E. Williams, Abundance and the Environmental Niche: Environmental Suitability Estimated from Niche Models Predicts the Upper Limit of Local Abundance. The American Naturalist 174, 282-291 (2009).

51. R. M. Nowak, E. P. Walker, Walker's Mammals of the World. (The Johns Hopkins University Press, Baltimore and London, 1999), vol. 1.

52. B. W. Brook, C. J. A. Bradshaw, Strength of evidence for density dependence in abundance time series of 1198 species. Ecology 87, 1445-1451 (2006).

53. R. J. Beverton, S. J. Holt, On the dynamics of exploited fish populations. Fishery Investigations (Great Britain, Ministry of Agriculture, Fisheries, and Food, London, 1957).

54. G. D. Sutherland, A. S. Harestad, K. Price, K. P. Lertzman, Scaling of natal dispersal distances in terrestrial birds and mammals. Conservation Ecology 4, (2000).

55. D. A. Fordham et al., Adapted conservation measures are required to save the Iberian lynx in a changing climate. Nat Clim Change 3, 899-903 (2013).

56. B. W. Brook, D. M. J. S. Bowman, Explaining the Pleistocene megafaunal extinctions: Models, chronologies, and assumptions. Proc Natl Acad Sci U S A 99, 14624 (2002).

57. G. M. Kilınç et al., Investigating Holocene human population history in North Asia using ancient mitogenomes. Scientific Reports 8, 8969 (2018). 
58. S. Shennan et al., Regional population collapse followed initial agriculture booms in midHolocene Europe. Nat Comm 4, 2486 (2013).

59. F. Saltré et al., Uncertainties in dating constrain model choice for inferring extinction time from fossil records. Quaternary Science Reviews 112, 128-137 (2015).

60. K. Csilléry, M. G. B. Blum, O. E. Gaggiotti, O. François, Approximate Bayesian Computation (ABC) in practice. Trends Ecol Evol 25, 410-418 (2010).

61. E. van der Vaart, M. A. Beaumont, A. S. A. Johnston, R. M. Sibly, Calibration and evaluation of individual-based models using Approximate Bayesian Computation. Ecol. Model. 312, 182-190 (2015).

62. M. A. McCarthy, C. Thompson, Expected minimum population size as a measure of threat. Anim. Conserv. 4, 351-355 (2001).

63. M. N. Wright, A. Ziegler, ranger: A Fast Implementation of Random Forests for High Dimensional Data in C++ and R. Journal of Statistical Software; Vol 1, Issue 1 (2017), (2017).

64. S.-I. Lee, Developing a bivariate spatial association measure: An integration of Pearson's $r$ and Moran's I. Journal of Geographical Systems 3, 369-385 (2001). 


\section{Supplementary Materials}

Fig. S1. Sampling effort for fossils of megafauna herbivores.

Fig. S2. Posterior distribution of parameter values for the best $1 \%$ of models based on Approximate Bayesian Computation.

Fig. S3. Accumulated local effects plot of the predictor variables for expected minimum abundance for Eurasia.

Fig. S4. Regional responses of woolly mammoths to humans and climate across time.

Fig. S5. Expected minimum abundance for the best models (1\% of all models run) between 21 and $3.8 \mathrm{ka} \mathrm{BP}$ for Asia, Beringia, and Europe.

Fig. S6. Effects of humans and climate at continental scales.

Fig. S7. Mammoth climate hypervolume.

Table S1. Significance tests between prior and posterior distributions.

Table S2. Expected minimum abundance at $3.8 \mathrm{ka} \mathrm{BP.}$

Table S3. Measures of synchrony and peak coincidence.

Movie S1. Projected range contraction of woolly mammoth in Eurasia from 21,000 BP.

Movie S2. Projected population densities of woolly mammoth in Eurasia from 21,000 BP.

Movie S3. Projected harvest rates of woolly mammoth in Eurasia from 21,000 BP.

Movie S4. Projected relative abundance of humans in Eurasia from 21,000 BP based on the Climate Informed Population Genetics Model (CISGEM) 


\section{Acknowledgments}

General: F. Saltré, K. Giampoudakis, A. Flórez-Rodríguez assisted with collating and analyzing the fossil record and ancient DNA.

Funding: D.A.F. and J.J.A. acknowledge funding from the Australian Research Council (FT140101192, DP180102392)

Author contributions: D.A.F, D.N.B. and C.R. conceived the idea for the paper. D.A.F. and S.C.B. did the analysis with support from H.R.A, B.W.B, S.H., A.M., K.T.S, J.J.A., J.P. and B.B. All authors contributed to writing the manuscript.

Competing interests: The authors declare no competing interests.

Data and materials availability: All data needed to evaluate the conclusions in the paper are present in the paper and/or the Supplementary Materials. All code to reproduce the population models is available at https://github.com/GlobalEcologyLab/Mammoth 


\section{Figures and Tables}

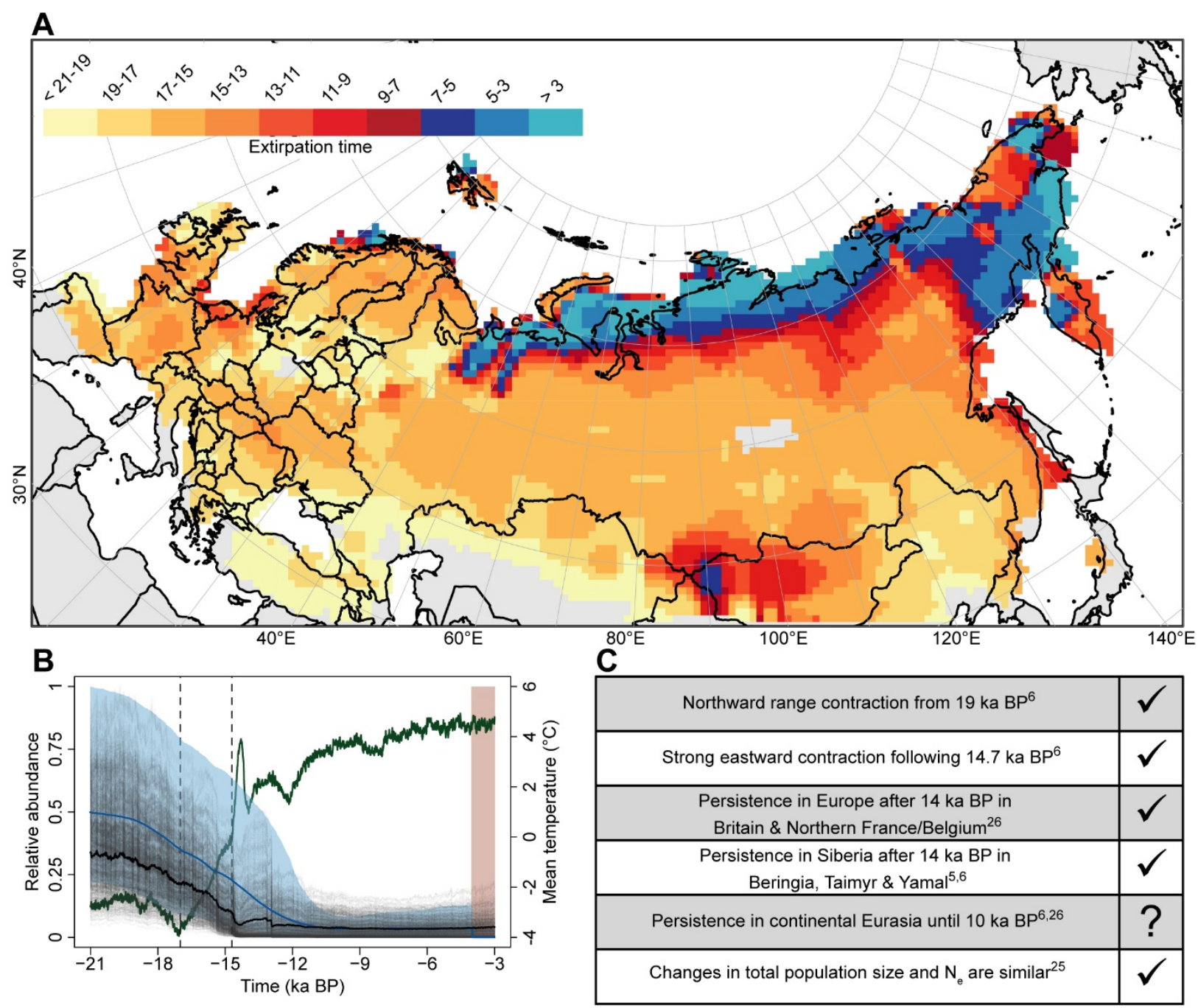

Fig. 1. Population decline and extinction of woolly mammoth in Eurasia. A) Timing of extirpation (model weighted) for woolly mammoth in Eurasia (ka BP). B) Ancient DNA estimates of effective population size $\left(\mathrm{N}_{\mathrm{e}}\right)$ (blue line $=$ mean, blue banding $\left.=95 \% \mathrm{CI}\right)$ and simulated total population size (black line $=$ weighted mean, grey lines $=$ range) rescaled between 0 and 1. Green line shows change in mean annual temperature for Eurasia. Vertical dashed lines show Heinrich 1 and 14.7 k climatic events. Red band shows estimated time of mammoth extinction. C) Well-established expectations and model agreement (ticks) and potential discrepancies (question mark). 


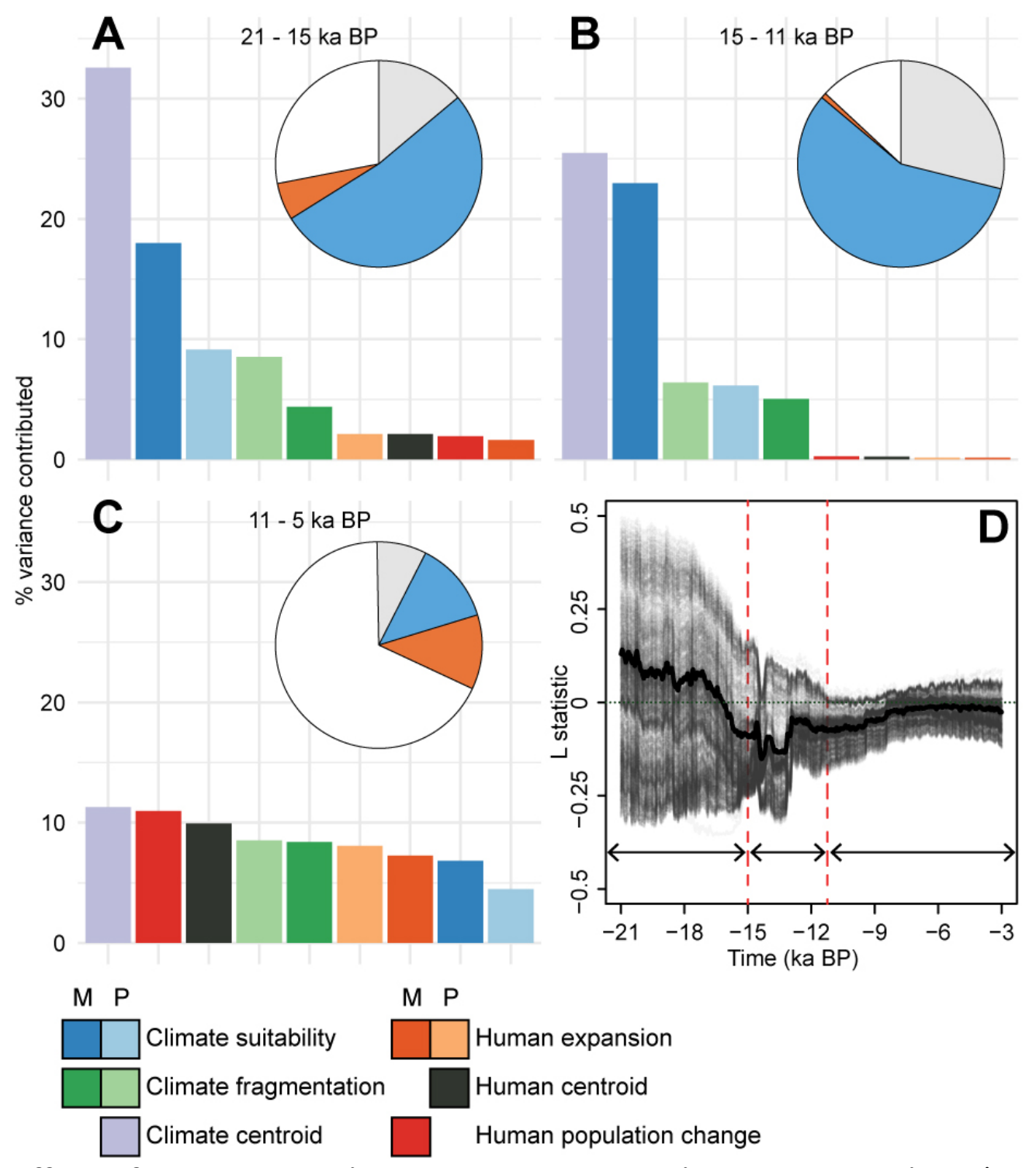

Fig. 2. Effects of humans and climate on mammoth decline across Eurasia. Drivers of expected minimum for the periods $21-15 \mathrm{ka} \mathrm{BP}(\mathbf{A}),<15-11 \mathrm{ka} \mathrm{BP}(\mathbf{B}),<11-5 \mathrm{ka} \mathrm{BP}(\mathbf{C})$ for the $1 \%$ best validated models. Pie charts show variance explained (\%) by climate (blue), humans (orange) and area of occupancy at the start of each period (grey). Histograms show contribution to explained variance for magnitude $(\mathrm{M})$ or pace $(\mathrm{P})$ of variables detailed in Appendix 2 of Fordham and Brown (30). White areas of pie chart represent unexplained variance. D) shows the relationship (Lee's L statistic) between human abundance and climate suitability for mammoths across time for Eurasia (black line = weighted mean, grey lines = individual model runs). Positive values indicate positive correlation, whilst negative values indicate a decoupling of the variables (negative correlation). Fig. S6 shows variable importance for area of occupancy. 

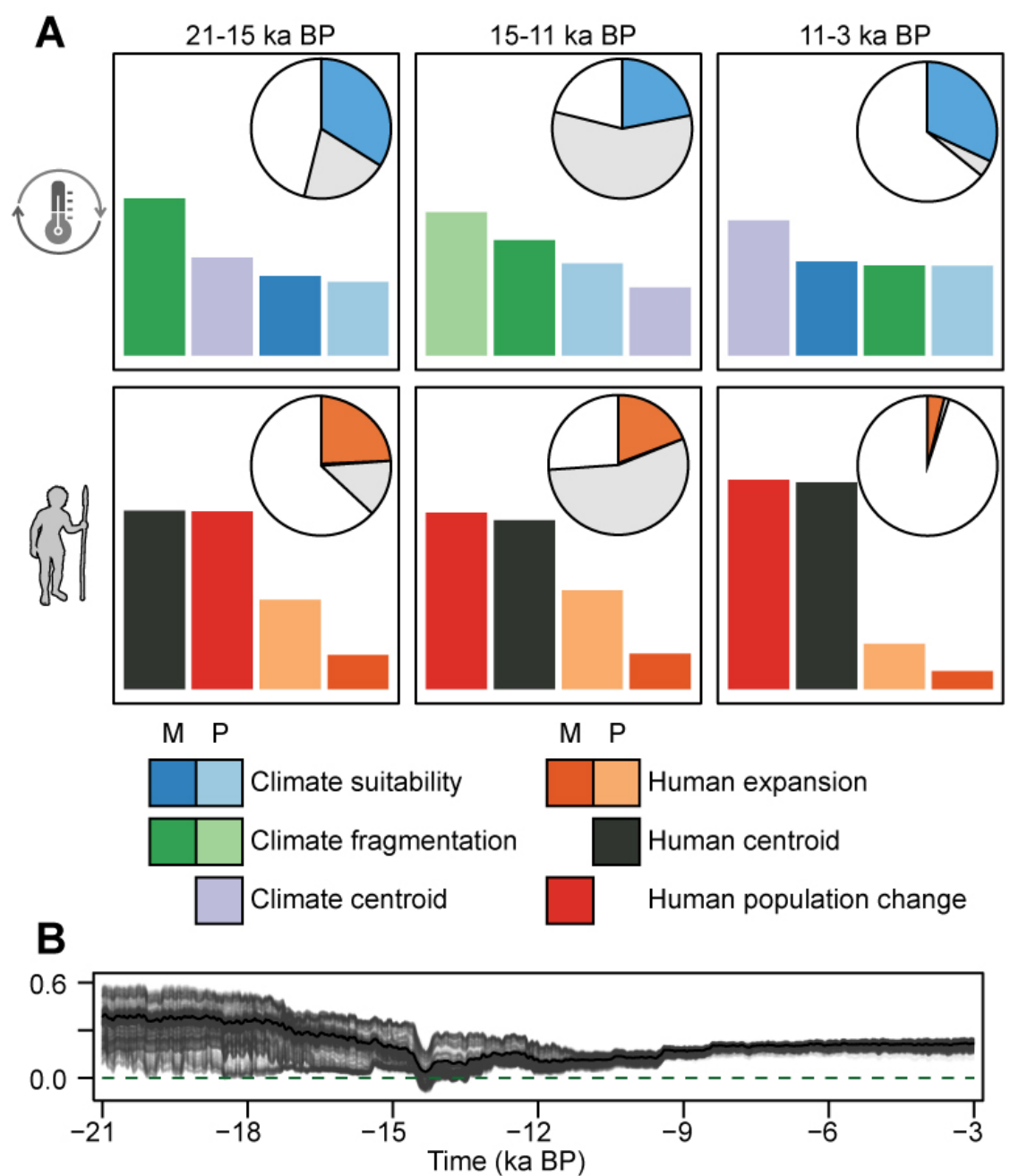

Fig. 3. Extinction risk of woolly mammoths in Europe due to humans and climate. A) Variable importance (histograms) and variance explained (pie charts) for climate (top row) and human parameters (middle row). Fig. 2 describes the legend. B) Lee's L statistic of autocorrelation between human abundance and climate suitability for mammoths. 

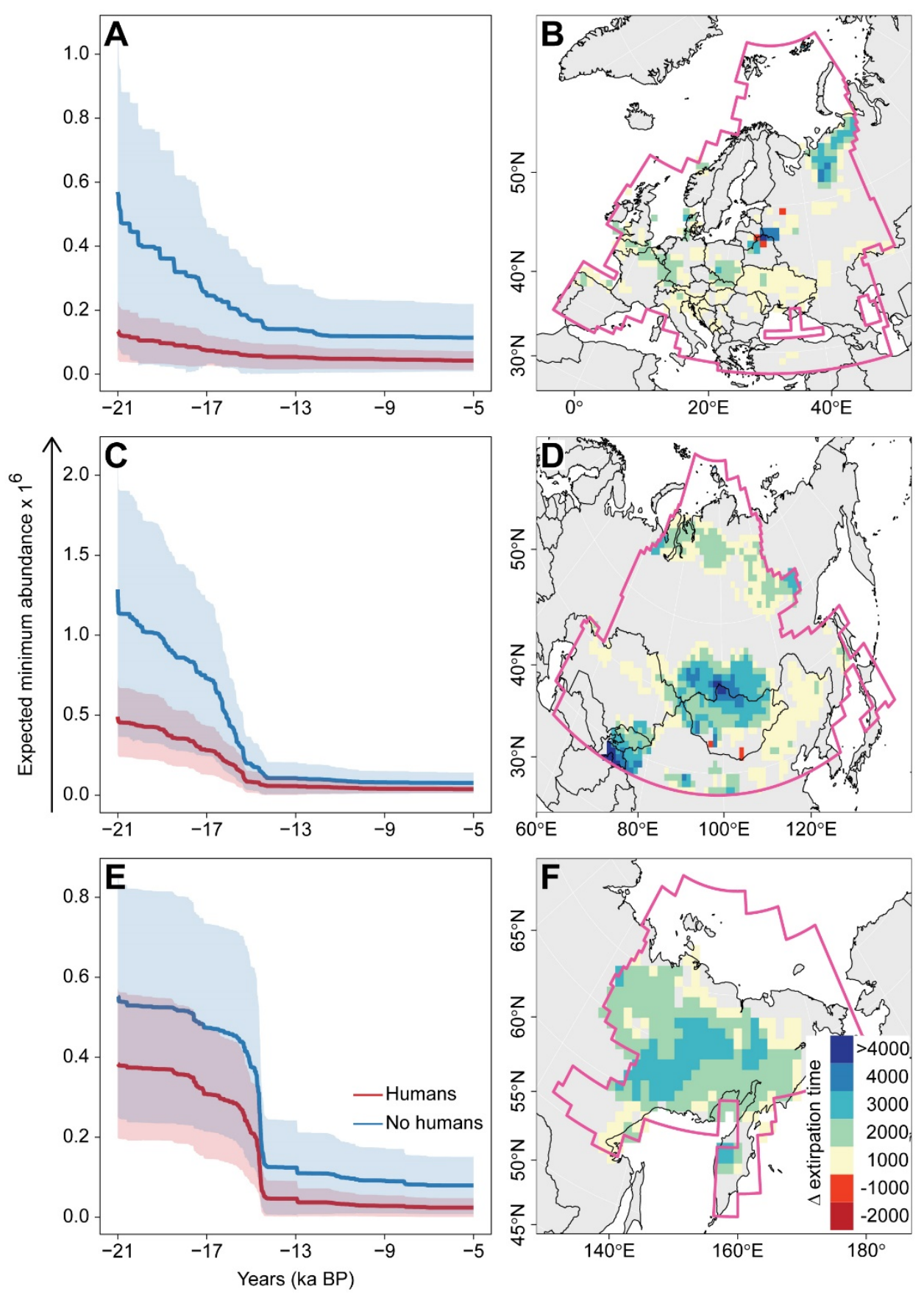

Fig. 4. Footprint of humans on the extinction dynamics of woolly mammoths. Relative change in expected minimum abundance of woolly mammoth in response to climate change and exploitation from $21 \mathrm{ka} \mathrm{BP}$ (Humans) and a counterfactual no-exploitation scenario (No humans) for Europe (A), Asia (C) and Beringia (E). Maps show the difference in timing of extirpation for woolly mammoths in the absence of hunting by humans (i.e. No humans - Humans) for Europe (B), Asia (D) and Beringia (F). Positive values indicate a later extirpation date in the absence of humans. Differences of \pm 500 years are not shown. Pink lines mark regional boundaries. 


\section{Supplementary Materials Supplementary Figures}

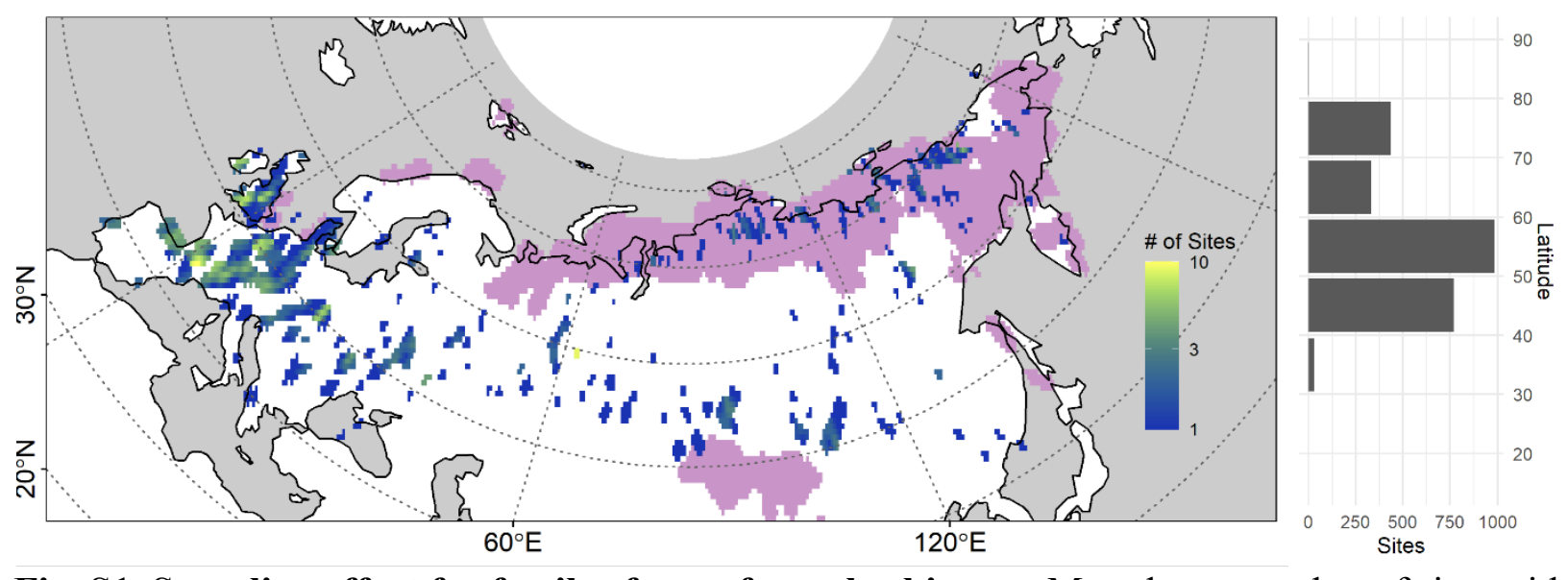

Fig. S1. Sampling effort for fossils of megafauna herbivores. Map shows number of sites with radiocarbon dated fossils of megafaunal herbivores in Eurasia at a $1^{\circ} \mathrm{x} 1^{\circ}$ grid cell resolution. Purple shows the projected Holocene range for the woolly mammoth. Histograms show the number of sites for each $10^{\circ}$ latitude band. The number of sites per grid cell is shown on a $\log$ scale. 
A

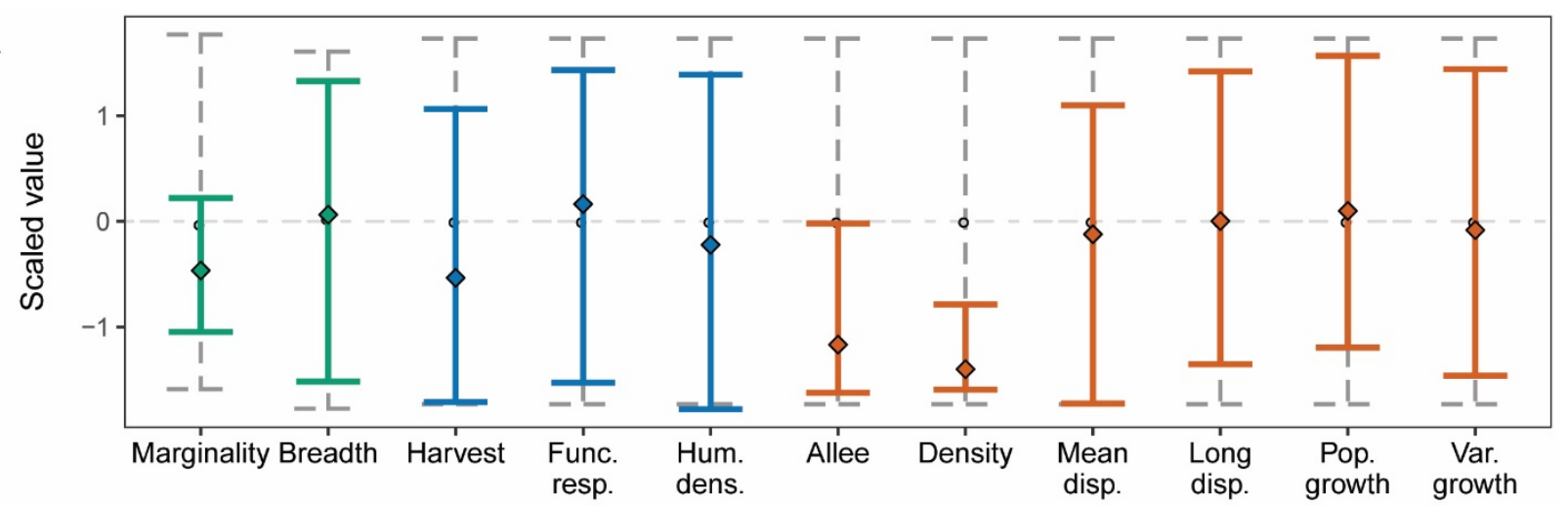

B

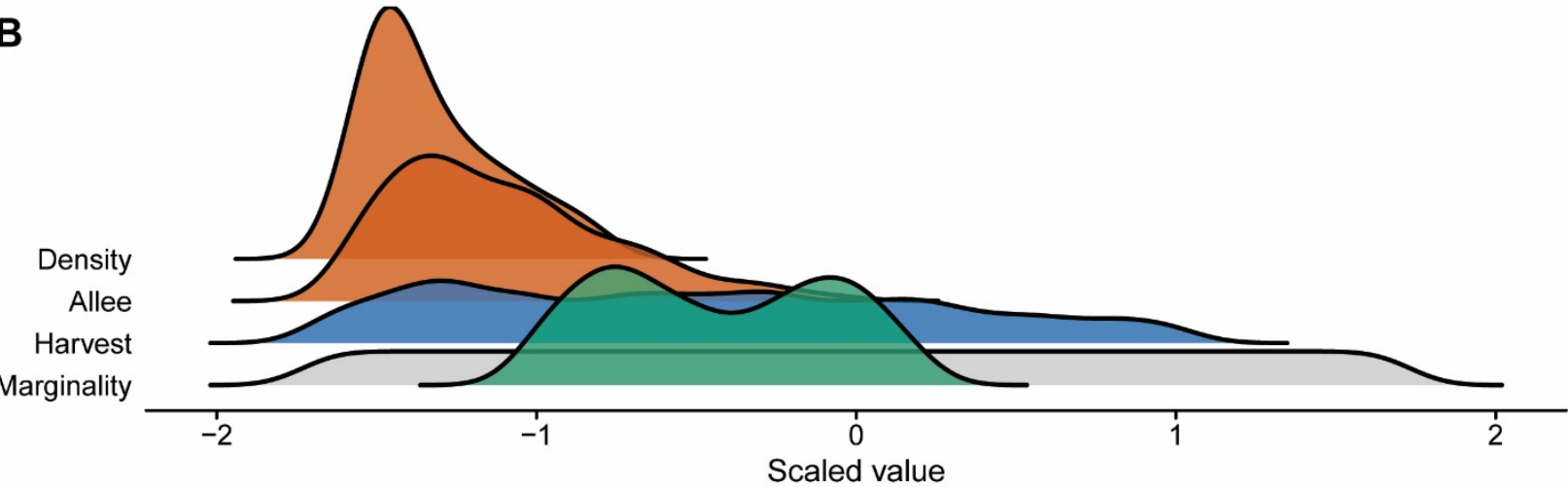

Fig. S2. Posterior distribution of parameter values for the best $1 \%$ of models based on Approximate Bayesian Computation. A) Dashed lines show prior values and solid lines posterior values for demographic processes (orange), and climate (green) and human drivers (blue). B) Bottom plot shows distribution of parameter values for the most influential parameters in the model. Demographic processes are: Allee effect, a threshold number of individuals, below which the population is assumed to be extinct; maximum number of mammoths in a grid cell with a maximum climate suitability (Density); maximum distance individuals can move in a dispersal event (Long disp.); mean percentage of the population that leaves a cell at a given time step (Mean disp.); maximum population growth rate (Pop growth); and standard deviation of population growth rate (Var growth). Climate drivers: distance between average conditions of the occupied niche and the average condition in the study region (Marginality); and breadth of climatic conditions the species can occupy (Breadth). Harvest parameters: percentage of the population that is harvested per generational time step (Harvest); $\mathrm{z}$ constant, which measures the extent to which harvest follows a Type II to Type III functional response (Harvest); and human abundance in a grid cell (Hum dens). See Appendix 3 in Fordham and Brown (30) for more details. 

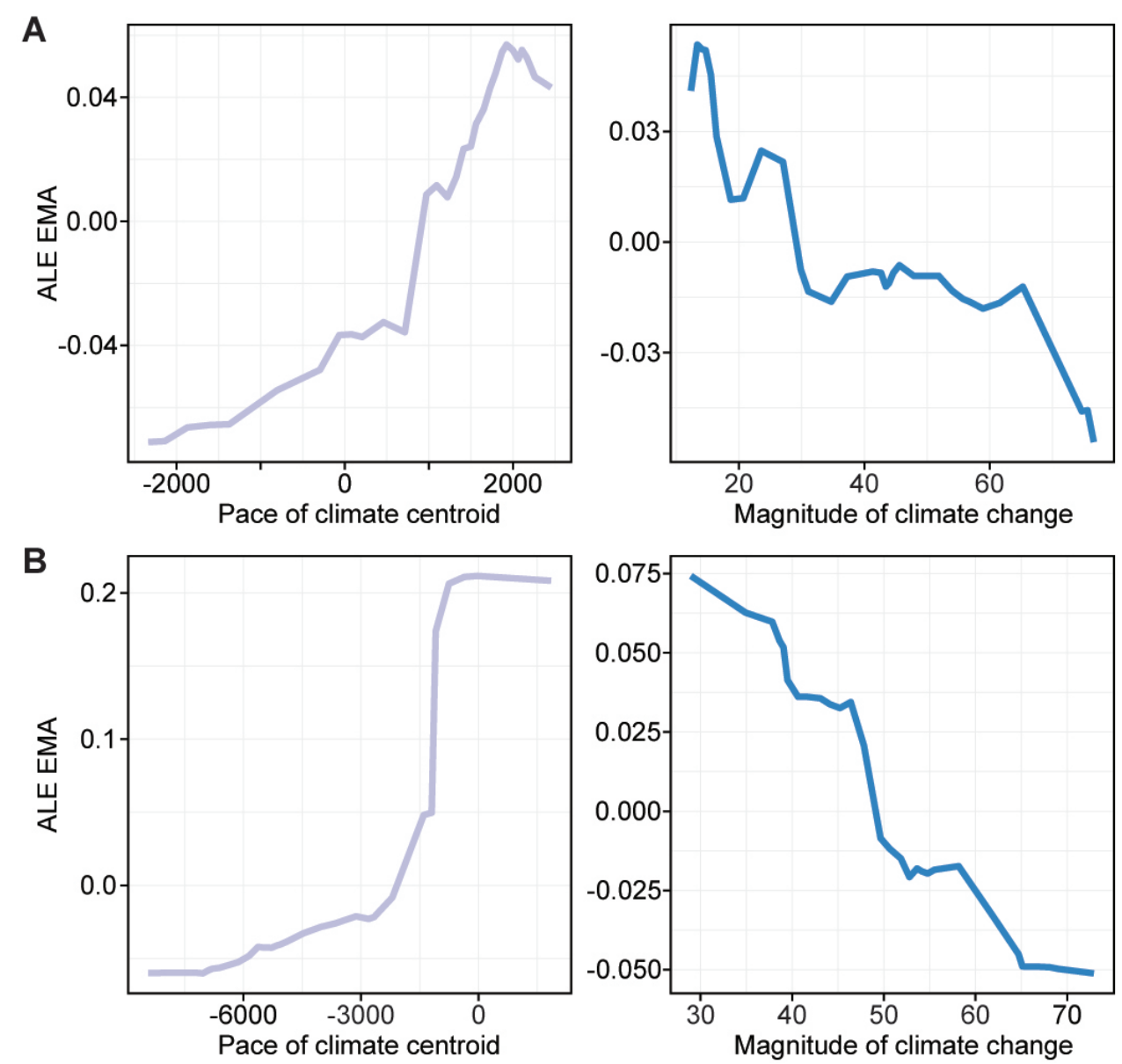

Fig. S3. Accumulated local effects plot of the predictor variables for expected minimum abundance for Eurasia. Plots show relationship for the two best predictors of expected minimum abundance for the period $21-15 \mathrm{ka} \mathrm{BP}$ (A) and $<15-11 \mathrm{ka}$ BP (B). See Appendix 4 (Fig 3-5) in Fordham and Brown (30) for local effects plots for all climate and human predictors. Pace of climate centroid indicates the movement of the centroid of climate suitability (a weighted measure based on the geographic distribution of climate-driven upper abundance; 30), with negative values indicating a southerly movement caused by the loss of suitable conditions in northern (low and high arctic) parts of the range. Magnitude of climate change is the \% change in climate suitability between the start and the end of each analysis period. The variables are described in detail in Appendix 2 of Fordham and Brown (30). 

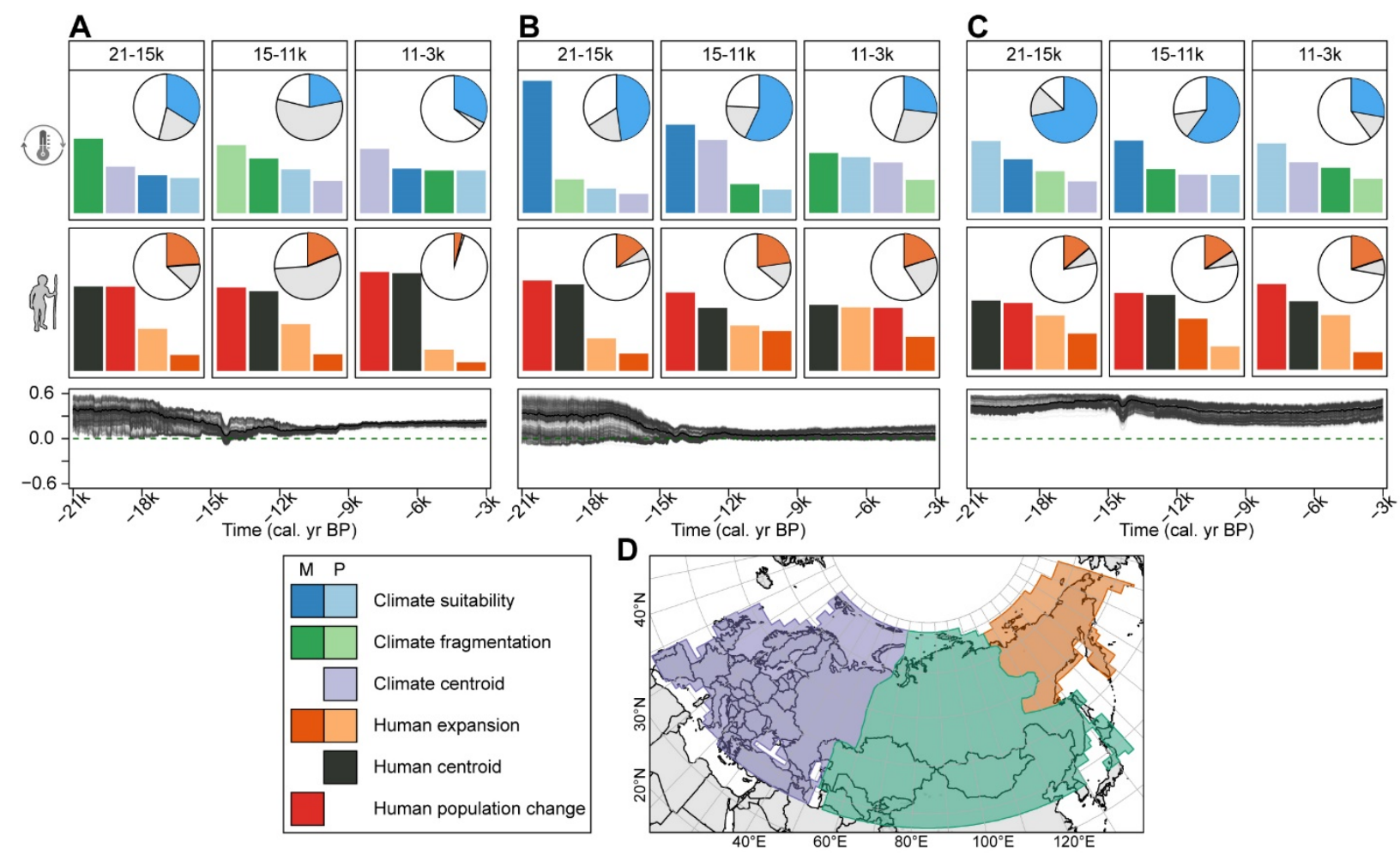

Fig. S4. Regional responses of woolly mammoths to humans and climate across time. Variable importance (histograms) and variance explained (pie charts) for expected minimum abundance in three distinct time periods for Europe (A), Asia (B) and Beringia (C) for the best $1 \%$ of validated models. Top row shows climate parameters, middle row shows human parameters, and bottom row shows Lee's L statistic of autocorrelation between human abundance and climate suitability for mammoths; see legend Fig 2. D) shows regions in A-C. Appendix 4 (Fig. 6 \& 7) in Fordham and Brown (30) shows variable importance for area of occupancy and combined effects of climate and humans. The variables are described in detail in Appendix 2 of Fordham and Brown (30). 


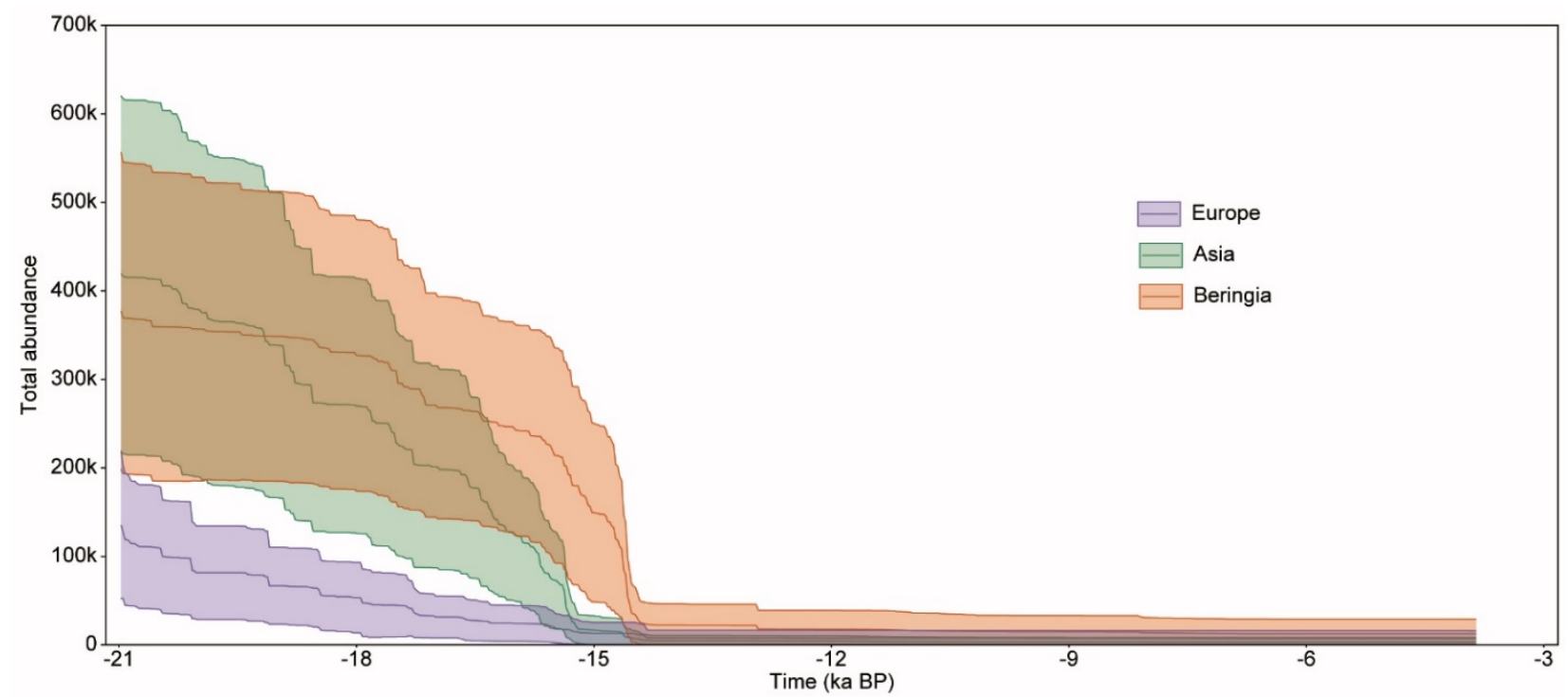

Fig. S5. Expected minimum abundance for the best models (1\% of all models run) between 21 and 3.8 ka BP for Asia, Beringia, and Europe. Values are weighted by model skill based on the ABC analysis (see Methods). Regions are shown in Fig. S4. 


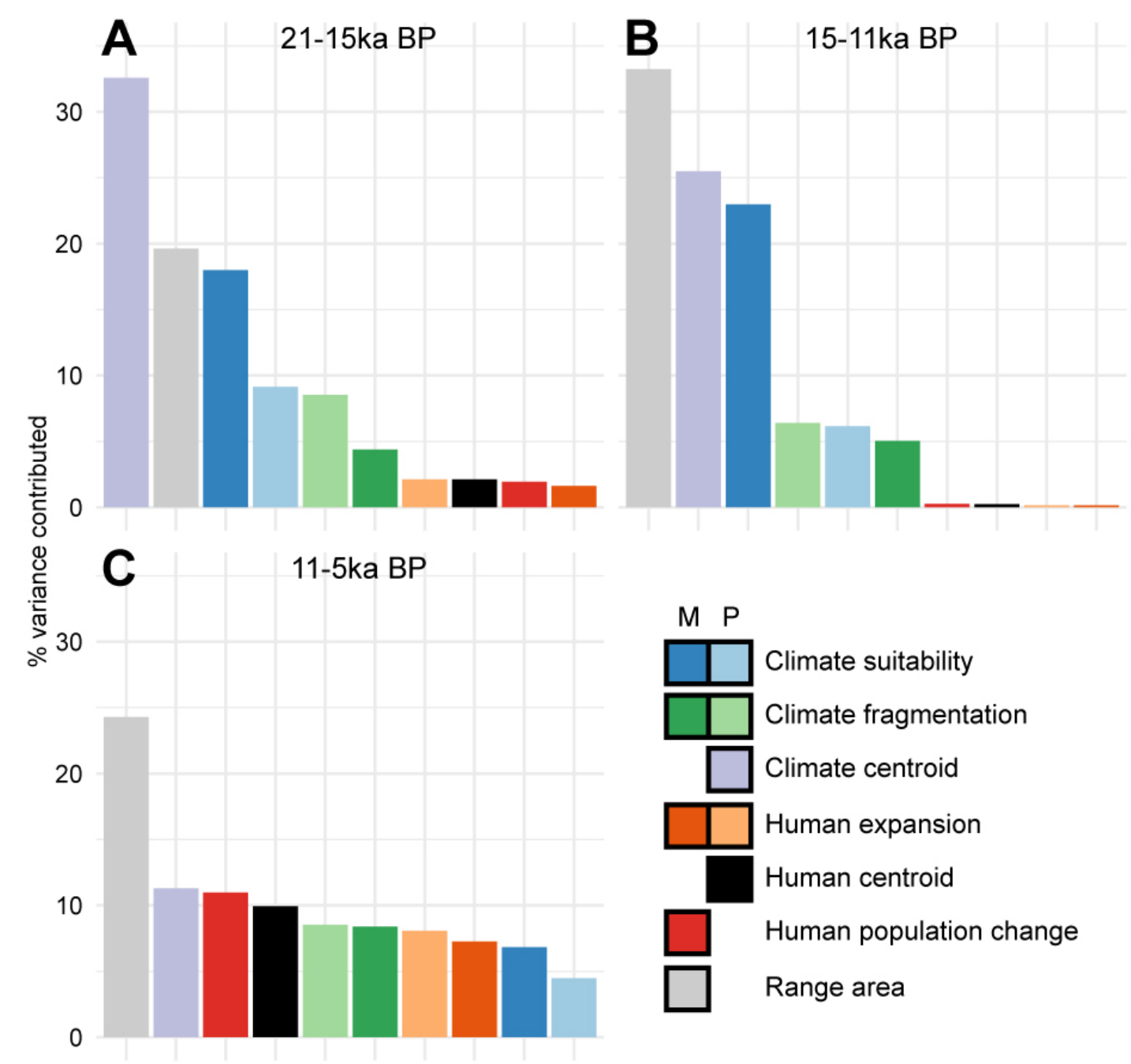

Fig. S6. Effects of humans and climate at continental scales. Variable importance for models examining combined effects of climate and humans on woolly mammoth expected minimum abundance (EMA) across Eurasia for the most skillful models based on the Approximate Bayesian Computation analysis (EMA $\sim f$ (climate, humans, range). Panels correspond to the following periods: $21-15 \mathrm{k} \mathrm{BP}(\mathbf{A}) ; 15 \mathrm{k}-11 \mathrm{k} \mathrm{BP}(\mathbf{B}) ; 11-5 \mathrm{k} \mathrm{BP}(\mathbf{C})$. Colors of each column correspond to color shown in the legend and represents either magnitude $(\mathrm{M})$ or pace $(\mathrm{P})$ of change of that variable over periods A-C. Range area is the area of occupancy at the start of a given period. The variables are described in detail in Appendix 2 of Fordham and Brown (30). 


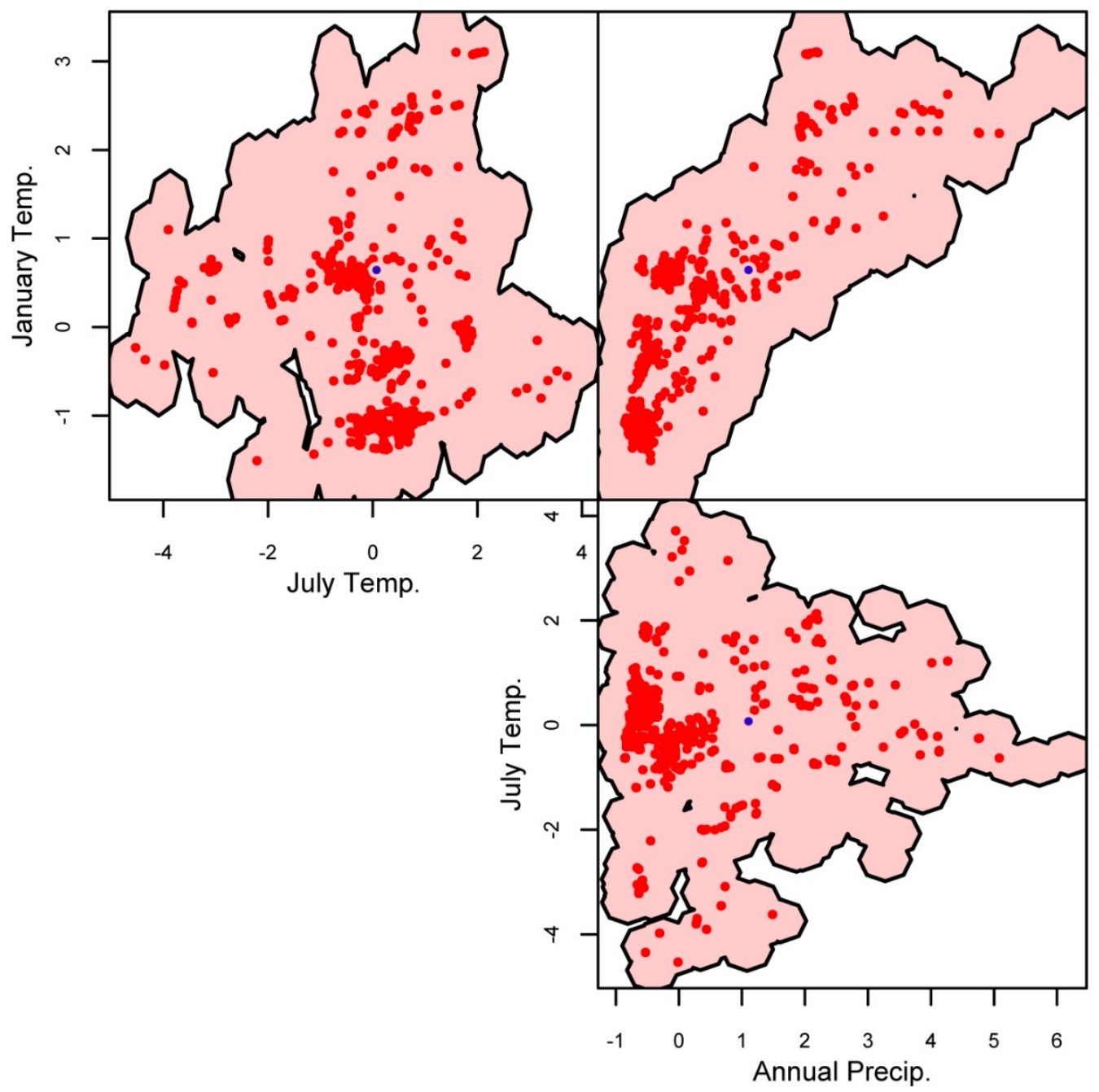

Fig. S7. Mammoth climate hypervolume. 2-dimensional representation of the 3-dimensional climatic hypervolume used for generating estimates of environmental suitability for the woolly mammoth. Red points represent paired fossil/climate data, with the centroids of each variable highlighted in blue. The solid red boundaries show the extent of the box hypervolume that was used to define the niche space. For details see the Appendix 1 in (30). 


\section{Supplementary Tables}

\begin{tabular}{l|rrr}
\multicolumn{1}{c}{ Variable } & Mean Prior & Mean Posterior & Bayes Factor \\
\hline Allee & $250( \pm 144.3)$ & $54( \pm 48)$ & 43.6 \\
Breadth & $0.9( \pm 0.4)$ & $0.8( \pm 0.2)$ & 0.5 \\
Density & $5313( \pm 2706)$ & $1956( \pm 714)$ & 27.1 \\
Func. Resp. & $1.5( \pm 0.3)$ & $1.6( \pm 0.3)$ & 0.8 \\
Harvest & $20( \pm 10)$ & $14( \pm 9)$ & 0.8 \\
Hum. Dens. & $0.5( \pm 0.3)$ & $0.4( \pm 0.3)$ & 1.0 \\
Long Dips. & $300( \pm 116)$ & $308( \pm 121)$ & 1.1 \\
Marginality & $1.3( \pm 2.5)$ & $1.6( \pm 1.8)$ & 0.4 \\
Mean Disp. & $15( \pm 6)$ & $16( \pm 6)$ & 1.0 \\
Pop. Growth & $4.1( \pm 1.6)$ & $4.1( \pm 1.5)$ & 0.9 \\
Var. Growth & $0.1( \pm 0.1)$ & $0.1( \pm 0.1)$ & 1.1
\end{tabular}

Table S1. Significance tests between prior and posterior distributions. Mean and standard deviation (parenthesis) for the prior and posterior distribution for the 11 variable parameters in the model. Bayes factors compare the mean and posterior distributions. Bayes factors greater than 1 suggest the posteriors are significantly different from the priors. All demographic parameters were scaled to prior to ABC analysis. Variables are described in Fig. S2. The lack of a significant difference between the prior and posterior distributions for Marginality and Breadth reflects the bimodal distribution of the posterior (see Fig. S2). 


\begin{tabular}{l|rrrrrrl}
\multicolumn{4}{c}{} & \multicolumn{3}{c}{ Baseline } & \multicolumn{4}{c}{ Climate only } & \multicolumn{1}{c}{ t-test } \\
\hline Region & Min & Max & Mean & Min & Max & Mean & \\
Europe & 0 & 16521 & 7579 & 0 & 47522 & 21313 & $t_{(1109.3)}=15.4$ \\
Asia & 0 & 8592 & 3353 & 0 & 28721 & 11364 & $t_{(1060.6)}=13.6$ \\
Beringia & 0 & 29712 & 13296 & 0 & 85428 & 39208 & $t_{(1123.1)}=16.3$
\end{tabular}

Table S2. Expected minimum abundance at 3.8 ka BP. Minimum (Min) and Maximum (Max) confidence intervals for expected minimum abundance based on \pm 1 standard deviation from the mean value for the baseline (climate + humans) and counterfactual scenario (climate only). Weighted t-test results are shown in the final column. All t-tests were significant at $\mathrm{p}<0.001$. Regions are shown in Fig. S4. 


\begin{tabular}{r|rrrrrr}
\multicolumn{2}{c}{$21-15$ ka BP } & \multicolumn{2}{c}{$15-11$ ka BP } & \multicolumn{2}{c}{$>11$ ka BP } \\
\hline Region & Synchrony & Peak & Synchrony & Peak & Synchrony & Peak \\
Europe & 0.16 & 0.60 & 0.12 & $0.52^{*}$ & 0.11 & $0.54^{*}$ \\
Asia & 0.21 & $0.68^{* *}$ & 0.14 & 0.56 & 0.12 & $0.55^{*}$ \\
Beringia & $0.29^{* *}$ & $0.77^{* *}$ & 0.14 & $0.57^{*}$ & 0.12 & $0.53^{*}$
\end{tabular}

Table S3. Measures of synchrony and peak coincidence. Phase synchrony (Synchrony) and peak coincidence (Peak) between simulations of population abundances with exploitation by humans (baseline scenario) and no exploitation ('no humans' counterfactual scenario) for four time periods. Both metrics range from 0-1, with higher values indicating an increase in the respective measures. Adjusted p-values significance levels are indicated in superscript $(*=p<$ $0.05 ; * * p<0.005)$ and are based on 999 permutations.

\section{Other supplementary material}

Movies S1 to S4 